\title{
Effect of Integrated Brain Utilization Program on the Academic Efficacy of Chinese Adolescents
}

\section{통합적 뇌 활용 프로그램이 중국 청소년의 학업 효능감에 미치는 영향}

Juwon $\mathrm{Oh}^{1}$

오주원 ${ }^{1}$

${ }^{1}$ Associate Professor, Department of Counseling Psychology, University of Brian Education, Korea, Jwoh@ube.ac.kr

\begin{abstract}
The purpose of this study is to verify the effect of integrated brain utilization programs on the academic efficacy of Chinese adolescents. To this end, an integrated brain utilization program was developed by considering the existing related studies. A total of 85 students in two classes (43 in the experimental group and 42 in the control group) in the 7th grade of Chinese youth were examined in terms of academic efficacy. The integrated brain utilization program was applied to the experimental group for a total of 30 sessions for 12 weeks, 2-3 sessions per week (1 session 30 minutes), and conducted a post-test after completion. For data analysis, Repeated Measurements ANOVA was used. As a result of the study, it was found that the integrated brain utilization program significantly improved the academic efficacy of Chinese adolescents. In particular, there were significant positive effects on the task difficulty factor and the overall factor, and no significant effects were found in the self-regulation factor and the confidence factor. The results of this study were aimed at Chinese adolescents with high academic stress in an educational environment similar to that of Korea. In terms of brain utilization, the integration of the three-layer brain including the subcortical area was investigated as an alternative to the current education focusing on the cortex. It is meaningful in that the implemented program was presented and its effectiveness was verified.
\end{abstract}

Keywords: Academic Afficacy, Chinese Adolescent, Integrated Brain Utilization, Polyvagal Theory, Vertical Integration

요약: 본 연구의 목적은 통합적 뇌활용 프로그램이 중국 청소년의 학업 효능감에 미치는 효과를 검증하는 것이다. 연구목적을 위하여 기존의 선행연구를 고찰하여 통합적 뇌활용 프로그램을 개발하였다. 연구대상으로 중국 청소년 7학년 두 개 학급 85명(실험집단 43명, 통제집단 42명)을 대상으로 학업 효능감 검사를 실시하였다. 실험집단은 1 주 $2-3$ 회기씩(1회기 30분) 12 주간 총 30회기에 걸쳐 통합적 뇌 활용 프로그램을 적용하였고, 종료 후 사후검사를 실시하였다. 자료 분석은 반복측정 분산분석(Repested Measures ANOVA)를 활용하였다. 연구 결과, 통합적 뇌활용 프로그램은 중국 청소년들의 학업 효능감을 유의미하게 향상하는 것으로 나타났다. 특히 과제 난이도 요인과 전체 요인에서 유의미한 긍정적 효과가 나타났으며, 자기조절 요인과 자신감 요인에서는 유의미한 효과가 나타나지

Received: June 28, 2021; $1^{\text {st }}$ Review Result: August 16, 2021; ${ }^{\text {nd }}$ Review Result: September 29, 2021 Accepted: October 31, 2021 
않았다. 이러한 본 연구의 결과는 우리나라와 유사한 교육적 환경에서 학업 스트레스가 높은 중국 청소년들을 대상으로, 두뇌 활용적 측면에서 피질에 초점을 맞추고 있는 현 교육에 대한 대안으로 피질하 영역을 포함한 3층 뇌의 통합을 구현한 프로그램을 제시하고 그 효과를 검증하였다는 측면에서 의의가 있다.

핵심어: 학업 효능감, 중국 청소년, 통합적 뇌 활용 프로그램, 다미주신경 이론, 수직적 통합

\section{1. 서론}

학습자들이 스스로 얼마나 학업을 잘 성취할 수 있는가에 대한 믿음을 갖는 것은 보다 나은 학습활동을 유도한다는 점에서 매우 중요하다. Bandura[1]는 이러한 믿음, 즉 개인이 어떠한 행동을 성공적으로 수행할 수 있다는 믿음을 가지는 것을 자기 효능감이라는 단어로 표현하였으며, 학업 효능감은 학업적 성취 상황이라는 한정적 부분에서 나타나는 자기효능감이라고 할 수 있다.

학업 효능감이 높은 학습자는 도전적 과제를 선정하고 주어진 과제를 성공적으로 수행하기 위해 더 많은 노력을 기울이며 어려움이 있어도 과제를 끈기 있게 지속하는 경향이 있다[2]. 청소년들에게 학업 효능감은 학교에서 주어지는 다양한 과제들을 자신에 대한 강한 믿음을 갖고 얼마나 끈기 있게 잘 수행하는가에 관한 것이다.

$\mathrm{OECD}$ 학업 성취도(PISA)2018년도 순위를 보면, 34개국 중 한국 청소년들의 읽기, 수학, 과학 순위는 모두 7 위 안에 들 정도로 높은 학업 성취율을 보여주고 있으며, 이처럼 PISA 성적이 높은 요인으로는 5.31 교육개혁 이후 일관되게 추진해 온 교육정책, 시대적 흐름을 반영한 교육과정 운영, 우수 교원 확보, 교실 수업 개선을 위한 각종 지원정책 등과 함께 공부를 잘하는 것에 대하여 큰 가치를 부여하고 있는 사회적 분위기와 높은 교육열에서 기인한 것을 꼽았다(OECD, PISA 2018 Results)[3].

그러나 이러한 사회적 분위기와 높은 교육열로 인해 청소년들이 학업에 대해 느끼는 스트레스를 고려할 때, 이렇게 높은 학업성취 결과가 우리 청소년들에게 바람직하지만은 않음을 알수있다. 한국보건복지포럼 김미숙[4]의 발표에 따르면 유엔아동기금(UNICEF)이 우리나라 청소년의 학업 스트레스 지수를 확인한 결과 $50.5 \%$ 로, 해당 연령대 한국 청소년 두 명 중의 한 명은 공부로 스트레스를 받는다는 것을 발표하였다. 이는 유엔아동기금에서 조사를 진행한 29 개국 중 가장 높은 수치이며, 조사 대상국 가운데 가장 낮은 학업 스트레스 지수인 $16.8 \%$ 를 나타낸 네덜란드의 세 배가 넘는 것이다. 따라서 학생들의 학교생활에 대한 삶의 질, 행복 및 만족 수준은 낮은 것이 현실이다.

한편, 21 세기 뇌의 시대를 맞이하여 국내외에서 뇌의 기능과 작용에 대한 지식을 인간의 교육에 접목하고자 하는 시도들이 '뇌 기반 교육'이라는 이름으로 확산되고 있는 실정이다. 이러한 학문이 추구하는 궁극적인 목적은 뇌의 기능과 작용에 부합하는 교육을 통해 더욱 효율적인 교육이 이루어질 수 있는 동시에 삶의 질을 향상하고자 하는 데 있다.

MaLean[5]의 삼위일체(trune brain)이론은 뇌에 대한 이해를 보다 용이하게 해준다. 삼위일체 이론에서는 뇌가 뇌간, 변연계 및 피질의 3 층으로 구성되어 있으며, 이 세 개의 층은 상호작용하며, 뇌의 많은 부분이 대부분의 기능에 직·간접적으로 관여한다고 본다. 학습 또한 두뇌의 상호작용적 측면을 고려할 때 보다 효과적인 학습이 가능하다. 
그러나 우리는 학습을 인지적 측면만을 지나치게 강조한 채 학습의 정서적 측면이나 신체적 측면 또는 감각적 측면에 대해서는 무시해왔다. 따라서, 우리의 학교 현장에서는 인지와 정서 및 신체감각이 분리될 수 없는 통합된 뇌의 실제 기전(mechanism)과는 달리 인지, 정서 및 신체 감각을 서로 분리된 것으로 본 나머지, 인지학습을 위한 교육과정에서 정서 및 신체감각의 기능을 활용하지 못하고 있었다는 점에서, 뇌의 구조와 기능에 부합한 3층 뇌의 통합적 교육이 절실히 요구된다 할 수 있다.

최근 트라우마 심리치료 기법의 하나로 신체 기반 체험중심(Somatic Experiencing)기법을 개발한 Peter Levin[6]은 인간의 건강한 정보처리 방식은 반드시 뇌의 3 층 구조, 즉, 본능(뇌간), 감정(변연계), 그리고 이성적 사고(피질) 사이를 유동적으로 오가는 방식이어야 한다고 강조한다. Levine에 따르면, 이 세 가지의 자원들이 조화를 이룰 때, 감각, 느낌 및 인지가 서로 소통하면서 소속감과 연결감을 느낄 수 있다고 본다. 또한, 내 몸에서 보내오는 감각들을 확인하고 내 몸과 연결되는 방법을 배우면서 우리는 우리가 가진 본능적인 파충류의 뇌 특성에 대해 경험적으로 이해할 수 있다. 이러한 감각적 체험은 포유류의 뇌가 생존만을 지향하는 것이 아니라, '우리는 우리다' 라는 감각으로 확장한다. 즉 우리는 여기에 함께 속해 있음을 자각하게 되고 물리적인 세계를 넘어서 유대감을 더해준다고 강조한다.

Levin에 따르면, 우리의 본능과 감정에 확실히 연결되지 않으면 우리는 이 지구, 가족 또는 그 무엇에도 자신이 연결되어 있고, 소속되어 있다는 느낌을 느낄 수가 없다. 소속감을 느끼는 것이 단절됨으로써 우리의 감정들은 외로움의 진공 속에서 몸부림치고, 우리의 합리적 정신은 연결이 아닌 단절에 기초한 환상을 만들어낸다. 자신이 모든 것들과 연결되어 있음을 느끼지 못할 때, 우리는 그것을 쉽게 파괴하거나 무시하게 된다. 인간이란 본래 타고나기를 서로 협동하고 사랑하는 존재이며 함께 일하는 것을 즐거워한다. 그러나 우리가 이 세 개의 뇌를 완전히 통합하지 않는다면 우리는 이러한 자신을 진정으로 이해할 수 없다.

세계적 신경과학자인 Daniel J. Siegel[7]은 그의 저서 '대인관계 신경생물학 (Interpersonal Neurobiology)' 에서, 통합된 신경계로부터 건강한 마음이 새롭게 나타난다고 하였다. 그는 우리의 피질은 피질과 피질 아래에 있는 피질하 영역을 통해서 들어오는 광범위한 신경 입력 신호를 조절하고 균형을 맞출 수 있다고 하였다. Siegel에 의하면, 우리가 몸, 뇌간 혹은 변연계에서 온 입력 신호를 알아차렸을 때 우리는 피질하 신호를 수직적으로 더 고위의 피질 영역과 연결함으로써 알아차림의 형태로 바꾸게 된다. 이것을 수직적 통합(vertical integration)이라고 한다. 우리의 비언어적, 비합리적 그리고 신체에 기반을 둔 피질하 신호가 우리의 삶에서 의미하는 것이 무엇인지를 아는 데 매우 중요한 기반을 형성해주기 때문이다. 수직적 통합에 장애가 발생하면 삶에 생동감이 없어진다.

수직적 통합을 촉진하는 방법에는 몸, 뇌간 및 변연계와 같은 아래에서 오는 신호를 잘 알아차릴 수 있도록 해야 하는데, 이는 근육과 뼈의 느낌이 어디서 오는지를 탐색하고, 장, 폐 그리고 심장과 같이 속이 빈 기관(내장)이 보내는 입력신호에서 오는 감각 등을 탐색하는 것을 의미한다. 뇌간에서 오는 입력신호는 싸움하기-도망가기(fight-flight) 혹은 얼어붙기(freeze) 반응과 같은 우리의 생존 반사를 활성화한다. 그리고 변연계에서 오는 신호는 사랑하는 사람과 헤어졌을 때, 그리고 연결을 간절히 바랄 때 나타나는 두려움, 절망감 같은 우리의 반응을 포함한다. 피질은 사람들이 이러한 신호들을 알아차리고 마음의 공간에 이들 신호를 수용하고 인내하는 것이 수직적 통합의 핵심이 
된다.

우리의 교육시스템에서는 뇌간이나 변연계에서 오는 감각을 알아차리는 훈련을 하지 않기 때문에, 미세한 감각의 흐름을 포착하기 어렵거나 뭔가 감지가 되더라도 처음에는 그냥 흘려보낼 수 있다. 그러나 연습을 통해 실제로 우리가 그 순간에 무엇을 느끼는지 알 수 있게 됨으로써 흘러가는 감각을 알아차리거나 고통스러워 피하고 싶었던 감각들도 잘 견뎌낼 수 있게 된다. 이런 훈련을 통하여 피질하 영역들에서 보내오는 신호들이 이제는 지혜로운 보물과 같은 존재로 느껴질 수 있다.

LeDoux[8]에 따르면, 우리의 뇌는 평상시에는 정보가 피질로 가서 정보를 명료화하고 정교화하여 편도가 적절하게 정서적으로 반응하게 되지만, 우리가 공포나 위협을 느낄 때는 신호가 피질로 가지 않고 곧바로 편도로 가서 즉각적인 반응을 하게 된다. Hart는 이러한 현상을 다운쉬프팅(downshifting)이라고 하였으며 위협이나 공포에 대한 뇌의 생존 반응이라고 보았다. 이렇게 뇌가 다운쉬프트하여 생존모드에 에너지를 쓸 경우, 정작 우리가 교육을 통해서 개발하고자 하는 고차원적인 사고 능력에는 에너지를 쓸 수 없게 되어, 학습이나 타인과의 관계 또는 놀이 등에 몰입하기 어렵게 된다.

이와 같은 원리로 스트레스 상황에서는 피질하 구조물들(변연계와 뇌간)이 활성화되는 반면에 우리가 학습을 위해 필요한 고차원적인 사고가 가능한 피질 부분은 비활성화되는데, 만성적으로 다운쉬프트를 경험할 경우에는 학습자의 대뇌피질 특히 전두엽에 부정적 영향을 미친다. 따라서 인간다운 특성이 충분히 개발되지 못하고, $\mathrm{Bloom}$ 이 제시하는 고차적인 학습능력도 개발되지 못할 것이다. 이와 관련하여 Beamish[9]는 오늘날의 많은 교육 문제는 다운쉬프트한 결과로 나타난 현상이라고 지적하면서, 학교에서의 모든 교육은 다운쉬프트를 막을 수 있는 방식으로 이루어져야 한다고 강조한다. 교육적 환경에서 다운쉬프트를 예방하는 방식은 '안전' 을 확보하는 것이다. 즉, 뇌간과 변연계가 안전하다고 인식이 되는 조건에서만 우리의 뇌는 피질을 활성화할 준비가 되는 것이다.

이러한 견해는 '뇌기반' 의 기본 개념이 '위협이 없는' 에서 출발해야 한다고 지적하는 Jensen[10] 과 Lloyd[11]의 견해와도 일맥상통한다. 우리 뇌는 위협을 받으면, 아드레날린, 코티졸, 배소프레신 등이 분비되어 학습을 지향하는 것이 아니라, 생존 지향적인 반응을 하게 되기 때문이다. 따라서, 최적의 학습을 위해서는 낮은 각성상태(relaxed alertness)가 필요하다고 주장하는데, 여기서는 낮은 각성상태란 바로 도전과 위협이 없는 상태를 말한다. 다시 말해, 낮은 각성상태에서는 아드레날린, 노르아드레날린, 코티졸 등의 신경전달물질이 일정한 농도를 유지하여 정서가 가장 안정된 상태이다.

과도한 스트레스를 지속해서 주는 학교 환경은 학습능력을 저하시키고 고차적인 사고를 불가능하게 할 뿐만 아니라, 학생들의 정서 상태를 악화 시켜 정서조절 문제를 야기할 수 있다. 이는 뇌의 우선순위가 생존이고, 위협을 받을 때 뇌는 고차적인 사고기능을 희생해서라도 생존모드로 돌아가기 때문이다. 따라서 심한 스트레스 상태에서는 일시적으로 학습이 이루어진다고 하더라도 사소한 사실을 기억하는 것으로만 한정되어 관계를 종합하고 포괄적인 이론을 이해하며 광범위한 자료를 통합하기가 어려워진다.

국내에서는 이러한 흐름에 맞게 '뇌기반 교육', '뇌활용 교육', '두뇌 발달 교육' , ‘뇌교육' 등 다양한 이름으로 신경과학에 바탕을 둔 교육 프로그램[12-16]이 개발되었고 그 효과가 검증되고 있다. 학습이나 학업 효능감과 관련한 연구들은, 이들 프로그램이 아동 및 청소년들의 학업성적, 학업 효능감, 인성, 창의성, 기억력, 수학, 
미술 및 음악 영역에서 유의미한 효과가 있음을 밝히고 있다. 이들 연구에서 언급하는 결과들은 뇌에 기반을 두고 3 층 뇌의 통합적 접근을 활용한 프로그램을 적용하였을 때 학업 성적뿐만 아니라 인성, 창의성, 인간관계 및 체력 등이 향상되었음을 일관성 있게 보고하고 있다. 또한, 이러한 결과들은 학생들이 공부하는 기계처럼 메마른 인간이 아닌 지, 정, 의를 갖춘 보다 인간적인 면모에 대해 언급하고 있다. 이러한 결과들은 학급의 전체적인 분위기가 밝아지고 인간관계가 개선되는 등의 효과가 나타나고 있다는 측면에서 고무적이라고 할 수 있다.

대학 입시에 큰 비중을 두고 학업적 성취능력을 중요시하는 분위기는 한국 사회뿐 아니라, 동일 문화권에 있는 중국 또한 마찬가지이다. 1978년 개혁개방 이후 놀라운 경제발전과 한 자녀 정책 등으로 중국 부모들의 대학입학 시험에 쏟는 교육열은 대단하다. 중국 부모들 역시 대학입학 시험인 가오카오(高考)에서 좋은 성적을 받아야 좋은 대학에 진학할 수 있고 좋은 대학에 진학해야 좋은 직업을 얻을 기회가 커진다고 생각하기는 우리나라와 마찬가지다. 이러한 환경 속에서 대학입학시험에 임하는 수험생들의 스트레스는 우리나라 학생들 못지않게 크다고 볼 수 있다.

본 연구에서는 대학입학 시험이라는 부담을 가진 중국 학생들을 대상으로 통합적 두뇌 활용 프로그램을 적용하고, 본 프로그램이 중국 청소년들의 학업 효능감 향상에 긍정적 영향을 미치는지 검증해보는 것을 목적으로 한다. 이러한 연구목적을 달성하기 위한 연구 문제는 다음과 같다.

연구문제: 통합적 뇌 활용 프로그램이 중국 청소년의 학업 효능감에 긍정적 영향을 미칠 것인가?

\section{2. 다미주신경 이론(Polyvagal Theory)}

다미주신경 이론은 Stephen Porges[17]가 제창한 이론으로 인간의 심신 건강에 있어서 안전감과 사회적 상호작용이 얼마나 중요한지 그리고 몸과 뇌 그리고 몸과 마음의 연결이 어떤 역할을 하는지에 대해 잘 설명하고 있다는 측면에서 뇌의 통합에 대한 이해를 돕는 매우 유용한 이론으로 본고에서 간략히 소개하고자 한다.

\section{1 다미주신경의 세 개의 하위 시스템}

학생들이 성적이 오르려면 공부에 집중해야 한다. 오랜 시간 집중하여 공부한 결과 성적이 오르기 때문이다. 집중하기 위한 신경학적 전제 조건은 '안전' 이다. 그러나, 서구문화에 바탕을 둔 우리의 교육환경은 안전에 대한 신체적 반응을 간과하고 있다. 교실에서 아이들을 면밀히 관찰해보면, 어떤 아이들은 안전하다고 느끼고 편안하게 앉아있는 반면, 어떤 아이들은 안전감이 결여된 과민한 행동을 한다. 교실에서 위험의 단서를 만성적으로 감지하는 아이들은 학습에 어려움을 겪기 쉬운 반면, 안전하다고 느끼는 아이들은 교사에게 집중하여 효과적으로 배우게 된다.

Stephen Porges[17]의 다미주신경 이론은 인간의 '안전' 에 대한 신경생리학적 기제에 대한 설명을 통해 어떻게 우리가 상호조절을 통해 안전이라는 개념을 형성해낼 수 있는지를 밝히고 있다. 스티븐 포지스의 다미주신경 이론에 대해 간략히 살펴봄으로써 학교 환경에서 학생들이 안전감을 확보하고 집중할 수 있도록 하기 위한 전제와 방법에 대해 알아보고자 한다.

미주신경(vagus nerve)은 뇌에서 출발한 12 개의 뇌신경 중 10 번째 신경을 말하는데, 이 
미주신경은 뇌신경 중 가장 길고 복잡한 구조를 가지고 있다. 미주신경은 자율신경 중 부교감 신경의 주요 신경으로 우리의 뇌를 몸과 연결하는 기능을 한다. 뇌의 신호를 내장기관들에 전달할 뿐만 아니라 내장기관들의 신호를 뇌에 전달하기도 하는 하향식(top-down)과 상향식(bottom-up) 기능 모두에 관여한다.

다미주신경 이론은 미주신경의 기제를 연구하는 과정에서 미주신경의 긍정적 측면과 부정적 측면이라는 두 가지 측면을 밝혀내게 되면서 다미주신경 이론으로 발전하게 되었다. 긍정적 측면은 심장으로 가는 미주신경 경로를 억제하는 기능을 해서 심장 박동 수를 느리게 하여 평온한 상태를 경험하게 하므로 항 스트레스 장치의 역할을 한다. 미주신경의 부정적 측면은 생명을 위협하는 서맥이나 기능적으로 심장을 정지 시켜 갑작스럽게 사망에 이르게 할 수도 있다. 이렇게 부교감 신경의 주요 신경인 미주신경이 보호적인 기능과 치명적 기능 두 가지 기능으로 분리되면서 여러 신체 기관을 조절하는 역할이 분리된다고 본다.

이 두 가지 미주신경 경로는 뇌간의 다른 영역에서 출발하는데 두 회로가 순차적으로 진화하면서 수초화의 유무로 구분되어 진다. 수초화가 안된 무수미주신경은 횡격막 아래 기관들의 주요 부교감신경 조절자로서 기능을 하며, 수초화가 이루어진 유수미주신경은 횡격막 위에 있는 기관들의 주요 부교감신경 조절자로 기능을 한다.

다미주신경 이론에서는 자율신경계가 단지 교감신경과 부교감신경이라는 단지 한 쌍의 대립적인 체계가 아니라 세 가지 하부체계로 구성된 위계적 시스템으로 개념화된다. 다미주신경 이론의 세 가지 하부체계는 진화 순서로 보면, 횡격막 아래 무수미주신경 경로, 교감신경계, 횡격막 위 유수미주신경 경로이다.

횡격막 아래 무수미주신경경로가 작동되면 인지기능이 중단되거나 신체적 고통을 더 이상 인지하지 못하는 상태가 되는데, 행동적으로는 셧다운(shutdown) 혹은 붕괴로 나타나며 파충류에게 잘 나타난다. 인간의 경우 해리(dissociation)와 관련된다. 심장 박동을 늦추고 호흡을 얕아지게 만들어 신진대사 자원을 보존하도록 한다. 이 시스템이 가동되면 상대방이나 자신이 겪고 있는 일이 더 이상 중요하게 느껴지지 않는다.

교감신경계는 긴장이나 스트레스 상황에서 활성화된다. 교감신경계가 활성화되면 싸움(fight)-도주(flight) 반응이 일어난다. 싸움-도주 반응은 긴장이나 스트레스 자극이 주어졌을 때 그 자극에 반응하기 위해 몸의 근육 활동력을 높이는 반응이다. 적에게 위협을 받는 상황이라면 적에게 대항하여 싸우거나 도망가거나 하기 위해 몸을 움직일 필요가 있다. 그 움직임을 준비하는 것이다. 심장 박동, 호흡 속도가 증가하고 위와 장의 움직임이 저하되며 혈관이 수축하고 근육 혈관이 팽창하는 등의 반응이 나타난다.

횡격막 위 유수미주신경 경로는 포유류의 보다 진화된 새로운 미주신경으로 수초화가 이루어진 미주신경이다. 유수미주신경은 얼굴과 머리 근육을 조절하는 뇌간 영역과 연결이 되어 있다. Porges에 따르면 포유동물은 점점 더 복잡해지는 사회적 삶을 잘 살아가기 위해 배 쪽 미주신경 복합체가 조절능력을 향상해 활성화된다. 예를 들어, 아기를 보면서 말을 건네고, 미소를 짓고, 관심을 나타내면 한창 발달 중이던 배 쪽 미주신경 복합체가 활성화되어 아기의 정서 자극 시스템이 주변 환경과 조화를 이루도록 돕는 역할을 하는 과정에서 유수미주신경 경로가 발달하게 된다. 수초화된 유수미주신경을 다른 말로 '스마트 미주(smart vagus)' 라고도 하며, 교감신경계 각성을 억제하고 조절하고 진정시키는 역할을 하며, 주변 사람에게 도움과 지원 및 편안함을 구한다. 
이 이론의 핵심은 자율신경계가 독립적인 세 개의 하부시스템(안전, 위험, 생명의 위협)으로 진화되어 왔고, 이 시스템은 위계적으로 작동한다는 것이다. 다미주 이론에서 사회참여체계(social engagement system)와 연결된 배 쪽 미주신경이 최적으로 작동할 때 '안전' 하다고 느낀다. 우리의 신경계가 사회참여체계에 있을 때는 편안함, 안전감, 호기심, 열린 마음, 연민, 마음 챙김, 연결감, 집중력 등 우리 인간이 성장하고 발전하기 위해 필요한 배움과 인간관계 및 문제 해결 등이 가능하다. 학습은 우리의 신경계가 이 시스템 안에 있을 때 가능하다.

이러한 위계적 순서에 따르면, 우리가 스트레스 자극을 받을 때, 가장 먼저 배 쪽 미주신경 복합체의 사회 참여 시스템이 작동하여 주변 사람들에게 도움을 요청하여 문제를 해결하려고 한다(안전). 그러나 이런 방식으로 해결되지 않을 때, 그 다음으로 교감신경계가 활성화되어 싸움-도주 모드로 들어가게 되면 우리의 신경계는 분노, 짜증, 좌절, 공황, 공포, 불안, 걱정 등의 정서를 느끼게 된다(위험). 이 단계에서는 '내가 할 수 있는' 수준에 머물지만, 스트레스 수준이 이보다 더 높게 지각된다면 우리의 신경계는 등 쪽 미주신경 복합체가 활성화되는 무수미주신경 경로에 따라 얼어붙음(freeze)모드로 들어간다. 얼어붙은 상태에서는 뇌가 '내가 할 수 없는' 수준으로 인지하여 셧다운(shutdown)상태가 되며 무감각, 우울, 무력감, 수치심, 무망감, 해리 등을 경험하게 된다(생명의 위협).

다미주 이론에서는 인식 없이 환경 속에서 위험을 평가하는 신경 프로세스를 '신경지(neuroception)' 라고 부른다[18][19]. 신경지는 환경의 위험을 의식적 과정 없이 평가한다. 지각(perception)은 인식하는 것과 의식적으로 탐지하는 것을 내포한다는 측면에서 신경지와는 다르다. 신경지는 인지적 과정이 아니다. 의식하기 전에 일어나는 신경계의 한 과정이라고 할 수 있다. 신경지는 환경에서 오는 다양한 단서에서 위험을 평가하고 여기에 적응적으로 반응하기 위해 자율신경 상태로 전환하는 신경회로에 의해 영향을 받는다.

다미주 이론에 따르면 신경계가 환경을 안전하다고 여길 때만 사회적 행동(놀이, 공부, 인간관계)과 정서조절을 지원하는 신경회로가 활성화되며, 이 회로들이 건강, 성장 및 회복에 관여한다. 따라서, 인간이 잠재적 역량을 최대한 개발하기 위해서는 우리의 신경지가 안전하다고 느껴야 하고 신경계의 안전한 상태는 사회적 행동뿐만 아니라 인간의 학습, 창조적 활동 및 대인관계를 맺기 위한 선결조건이라고 할 수 있다. Ruby Jo Walker[20]의 다음 그림은 다미주신경 이론을 잘 나타내고 있다[그림1].

\section{2 사회 참여 시스템 활성화 방안}

현재 우리의 교육 기관들이 안전한 상태를 조성하기 위해 무엇을 하고 있는가? 안전에 대한 개인적 필요를 확보하기 위해 우리 문화와 사회는 무엇을 우선순위에 두는가? 우리는 안전감을 깨뜨리는 것들이 어떤 특징을 지니는지 이해하고, 위험과 생명의 위협에 우리의 신경계가 얼마나 취약한지 이해한다면, 우리가 교육기관에서 신경계의 방어체계를 완화하고, 강력한 사회적 유대감을 형성하도록 해주며, 건강과 성장과 회복을 지원하는 사회적 환경의 중요성을 인식할 것이다.

다미주 관점에서 안전감은 교육을 포함해 심리 치료적 효과에 영향을 미치는 중요한 중재 요인이다. 효과적이고 효율적인 정서적 안정을 위해서는 자율신경계가 방어 상태에 있지 않도록 하는 것이 필수적이라는 것이다. 배 쪽 미주 경로를 통해 사회참여체계를 
활성화하는 것은 자율신경계가 건강, 성장, 배움 및 회복을 돕도록 한다. 이렇게 안전한 상태에서는 자율신경계가 쉽게 방어 상태에 빠지지 않는다.

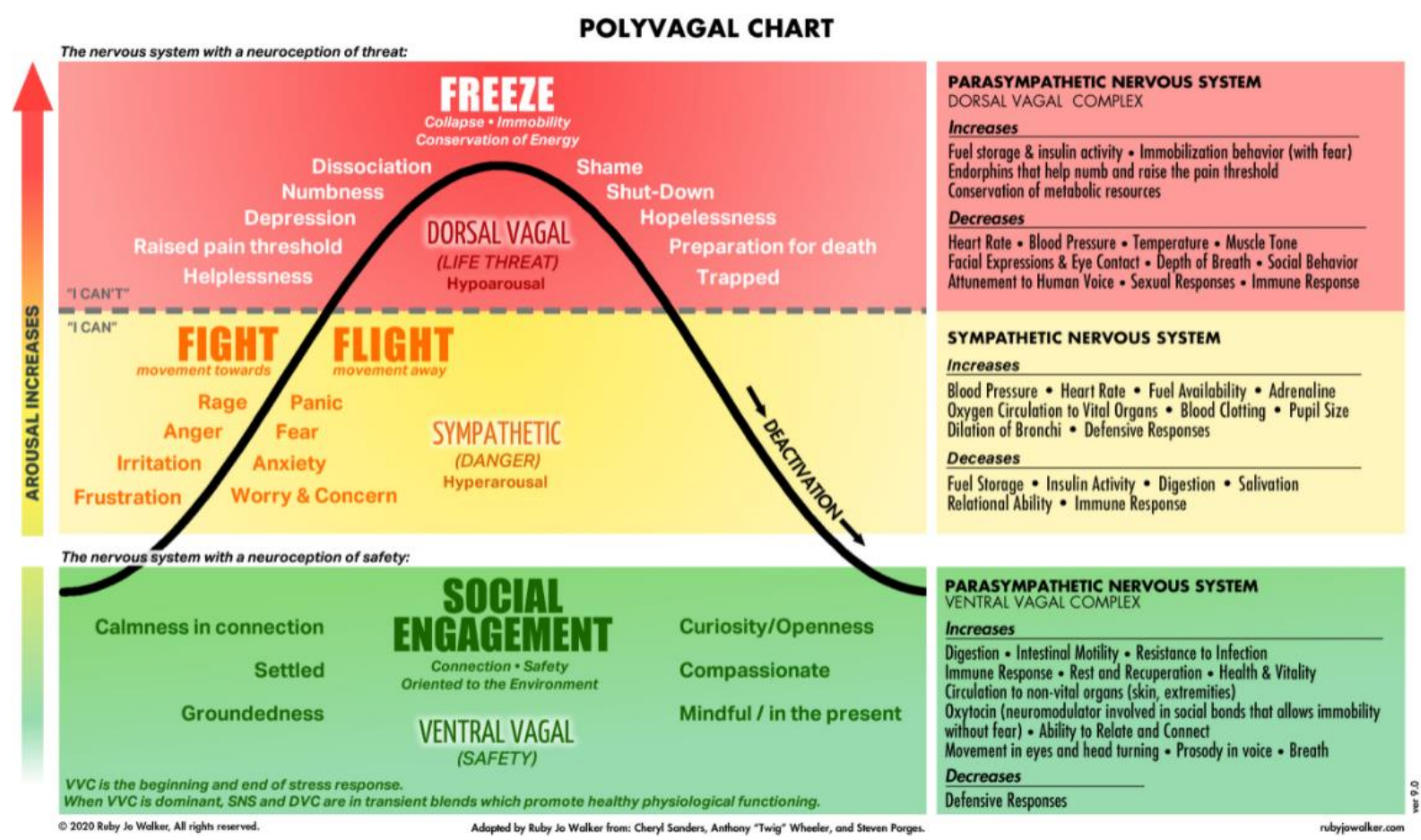

[그림 1] 다미주신경 챠트

[Fig. 1] Polyvagal Chart

다미주 이론에서는 사회참여 시스템을 활성화하기 위한 방안으로 좋은 인간관계를 통한 연결감, 요가와 같은 신체적 움직임, 호흡, 명상 및 놀이를 추천한다. 인간에게 원초적인 생물학적 지상과제는 다른 사람과 연결되는 것이다. 타인의 욕구를 존중하여 서로를 마주 보며 타인과 집단과 연결되어 있다는 느낌을 받을 때 안전하다고 느낀다.

학교 환경에서 학생들이 다른 학생들 또는 선생님들과 만나서 서로 얼굴을 바라보며 언어를 통해 대화하면서 보고, 듣고 느끼는 사회적 상호작용을 하는 동안 신체적 상태와 정서적 과정 사이에 양방향 소통이 역동적으로 일어나는 예이다. 사회적 상호작용을 통해 서로를 지원하고 생리적 상태의 상호조절이 가능하도록 하려면 두 사람의 사회 참여 체계에서 표현되는 신호들이 서로에게 안전과 신뢰를 보여줘야 한다. 이러한 안전과 신뢰가 일어날 때, 실제 참가자들은 학생과 교사 또는 아이와 부모 등 상대방과의 관계에서 안전을 느낄 수 있다. Porges는 이를 비유적으로 '자물쇠와 열쇠가 맞으면 잠금이 열리는 것과 같다' 고 표현한다[21].

학교 환경에서 학생들이 친구들을 어떻게 바라보는가 하는 것은 이러한 연결 역량의 중요한 면이다. 우리의 신경지는 상대에게서 전달되는 상호 이해와 느낌 및 의도를 나누는 미세한 신호들을 포착한다. 이런 신호들은 억양이나 발성의 운율에 따라 변하기도 하면서 생리적 상태를 소통한다. 즉, 생리적 상태가 평안할 때만 우리는 서로 안전신호를 나눌 수 있다.

다미주 모델의 긍정적 특징은 신경계의 방어전략을 완화하고 사회참여 시스템을 
활성화 할 수 있는 학교 환경을 만들에 내는 데 시사점을 제공한다는 것이다. 신경지의 특징은 사회참여체계를 작동한다는 것인데, 이때 사회참여 체계는 포유류만의 독창적 혁신인 자율신경계의 신경조절로 사회적 상호작용을 가능하게 하여 생리적 상태를 진정시키고 건강과 성장과 회복을 지원한다.

다미주 이론은 신체와 뇌 사이, 그리고 신체와 심리적 과정 사이에 신경생물학적 연결고리를 제공한다. 자기 자신에 대해 느끼는 감각은 몸에 뿌리내리고 깊이 연관되어 있는데[22], 신체감각을 느끼고 해석하지 못하면 자기 자신을 제대로 알 수 없다. 즉 우리는 그 감각을 인지하고 그에 따라 행동하면서 안전한 방향을 찾아 나아가야 한다. 감각이 둔화되면 자신의 몸 내부에서 벌어지는 일을 인식하지 못하고 그로 인해 온전하게 감각을 느끼지 못한다.

몸을 움직이는 요가 프로그램은 요가 종류에 따라 강조하는 부분에 차이가 있지만, 핵심 요소는 스트레칭, 호흡 및 명상이다. 요가는 자기와의 관계를 형성해 주는 효과가 뛰어나다. 요가에서는 호흡과 순간순간 발생하는 감각에 집중하게 된다. 요가 강사들은

'몸의 감각에 집중하세요' , '그 감각에 어떤 변화가 일어나는지 지켜보세요' , '몸에서 느껴지는 고통에 잠시만 더 머물러보세요. 그리고 그 고통을 느껴보세요' 와 같은 말을 끊임없이 반복한다. 이를 통해, 어떤 자세를 취했을 때, 불안, 균형을 잃게 되는지, 감각이 어떻게 바뀌는지 실험해볼 수 있고, 심호흡하면 어깨의 긴장이 풀어지는지, 숨을 내쉴 때 집중하면 마음이 평온해지는지 등 신체 내부에서 일어나는 감각의 변화를 알아차리면서 우리의 몸과 감정이 연결되어 있음을 깨달을 수 있다[23].

또한, 호흡 수련을 통해 무척 간단하지만, 대단히 심오한 경험을 할 수 있다. 느리고 깊은 날숨은 미주신경이 교감신경계를 억제하도록 자극함으로써 우리를 진정시킨다. 천천히 숨을 내쉬는 동안 발성을 하고 노래 부르는 것, 관악기 연주를 통해 천천히 숨을 내쉬는 것, 중단 없이 계속 길게 이야기하는 것도 진정에 도움이 된다.

마음챙김 명상은 생리학적 자기 조절에 중요한 역할을 하는 뇌 영역에 긍정적인 영향을 준다는 사실은 이미 널리 밝혀져 있다. 마음챙김 명상의 특성은 선호 및 선택에 관계없이 주의를 기울이는 것이다. 호기심은 마음챙김적 탐색의 주요한 특성이다. 마음챙김은 뇌를 변화시킨다고 여겨지는데, 마음챙김을 통해 현재 경험을 구성하고 있는 요소들을 탐색한다. 주의가 가는 곳에 신경의 점화(neural firing)가 일어난다, 뉴런 점화가 있는 곳에 새로운 연결이 만들어진다[24].

종합하면, 신경과학적 입장에서 보면 학교환경에서 학생들이 학업에 몰두하기 위해서는 신경지가 안전하다고 느끼는 것이 중요하다. 그러나 서구문화에 기반을 둔 교육적 환경에서는 우리가 신체적 차원에서 일어나는 몸의 느낌이나 움직임을 무시하거나 거부해야 하는 입장이었다. 오랜 시간에 걸쳐 몸의 반응을 존중하지 않고 내장이 보내는 위험의 느낌을 무시하는 일은 뇌와 신체 그리고 신체와 마음 사이의 양방향적 신경피드백을 주는 미주신경의 기능을 약화시켜 효율적으로 뇌를 활용하지 못할 뿐만 아니라 결국에는 질병에 이르게 할 수 있다.

그러나 뇌와 내장을 연결하는 미주신경이 양방향적 소통을 하기 때문에 우리가 의식적으로 인식하지는 못할지라도 신경지는 위험을 감지할 수 있다. 따라서, 우리가 우리 몸의 생리적 변화에 관심을 가지고 주의를 기울인다면 내장 기관에 의한 내부수용감각이 보내는 생리적 변화를 알아차리고 적절한 대처를 할 수 있을 것이다. 본 연구에서는 이러한 이론에 근거하여 다미주신경 이론에서 제시하는 위험 요소가 제거된 학교 환경으로 좋은 인간관계, 신체적 움직임, 호흡, 명상 및 놀이 등과 같은 요소들이 
포함되면서 신체감각, 정서 및 인지가 조화를 이룰 수 있는 통합적 두뇌작용의 원리에 기반한 프로그램의 효과를 검증해보고자 한다.

\section{3. 연구방법}

\section{1 연구대상}

본 연구의 대상으로는 중국 푸동시 소재 7학년 학생 85명(남:42 여:43)이다. 연구대상 중 불성실한 응답자 또는 사전, 사후, 추후 검사 중 하나라도 작성하지 않은 학생의 경우 분석대상에서 제외하여 총 66사례가 분석되었다.

\section{2 실험설계}

실험설계는 통제집단 사전 사후설계를 사용하였다. 통합적 뇌활용 프로그램이 적용되기 전에 실험집단과 통제집단을 대상으로 학업 효능감 검사를 실시한 후, 실험집단에는 ‘통합적 뇌활용 프로그램' 을 실시하였으며, 통제집단에는 통합적 뇌활용 프로그램을 실시하지 않았다. 통합적 뇌활용 프로그램이 적용되는 3 개월 동안 1 주 2 3회(1회기 30분)씩 12주 총 30회가 적용되었다. 프로그램 적용 후 실험집단과 통제집단 모두를 대상으로 사후검사를, 프로그램이 종료된 2개월 후 추후 검사를 실시하였다.

\section{3 측정도구}

학업 효능감은 학생이 과제수행에 필요한 행위를 조직하고 실행해 나가는 자신의 능력에 대한 판단이다. 학업 효능감을 측정하기 위한 측정 도구는 장민혜[25]연구를 그대로 사용하였다. 이 척도의 하위요인으로 과제 난이도(10문항), 자기조절(10문항) 및 자신감(8문항)으로 구성되며, 총 28문항이다. 척도의 신뢰도는 Cronbach's a .893으로 신뢰로운 수준이었다. '과제 난이도' 는 개인이 어떤 수행상황에서 목표를 설정할 때 어떤 수준의 난이도를 선호하는가를 측정하고 개인이 통제하고 다룰 수 있다고 생각하는 도전적이고 구체적인 목표를 선택하는 정도를 의미한다. '자기조절 효능감' 은 개인이 자기관찰, 자기판단, 자기 반응과 같은 자기 조절적 기제를 잘 수행할 수 있는가에 대한 효능감을 의미한다. '자신감' 은 학습자가 자신의 학습 능력에 대해 보이는 개인의 확신 또는 신념을 뜻한다. 점수가 높을수록 해당영역의 효율성이 높음을 의미한다.

\section{4 프로그램}

‘통합적 뇌 활용 프로그램’ 은 중국 유다(U-DAP Solution China)에서 뇌교육(Brain Education)[26]을 바탕으로 프로그램을 구성하고 트레이너를 파견하여 자료가 수집되었다. 본 프로그램은 이론적 이해보다는 체험 중심의 교육으로 몸과 마음과 정신이 상호 작용한다는 원리를 바탕으로 뇌체조, 호흡 및 명상을 중심으로 신체(감각), 정서 및 인지를 자극하여 뇌를 효과적으로 활성화 할 수 있도록 구성되어있다.

프로그램의 목적은 신체(감각), 정서 및 인지적 조건을 최적의 상태로 만들어 심신이 건강하고 행복하며 자신이 가진 잠재능력을 최대한 발휘하여 자기성장을 도모하는 데 
있다. 이러한 목적으로 개발된 통합적 뇌 활용 프로그램은 신체, 정서 및 인지라는 세 가지 영역으로 구성되어 있으며 세부적인 교육목표는 [표 1]과 같다.

[표 1] 통합적 뇌 활용 프로그램의 영역별 세부 교육 목표

[Table 1] Detailed Educational Goals for Each Area of the Integrated Brain Utilization Program

\begin{tabular}{|c|c|}
\hline 영역 & 세부 교육 목표 \\
\hline \multirow{3}{*}{ 신체(체력) } & $\begin{array}{c}\text { 자신의 몸을 의도대로 쓸 수 있는 상태를 말한다. 우리 몸 전체의 감각을 깨우는 '감각 } \\
\text { 몸과 연결된 뇌 부위를 깨우고 혈액순환을 원활하게 하여, 몸과 마음의 이완 상태를 } \\
\text { 유도한다. }\end{array}$ \\
\hline 정서(심력) & $\begin{array}{c}\text { 명상과 호흡을 통하여 정서적 안정을 유도하고, 삶의 목표와 비전을 설정하고 긍정 } \\
\text { 마인드를 향상시켜 나 자신과의 관계 및 타인과의 관계를 넘어 자연과의 관계를 조화롭게 } \\
\text { 확립한다. }\end{array}$ \\
\hline 인지(뇌력) & $\begin{array}{c}\text { 뇌의 구조와 기능에 대한 이해 및 두뇌 발달의 원리에 대한 이해를 통해, 집중력을 } \\
\text { 향상시키고, 부정적인 정보를 선택하는 습관을 바꾸어 긍정적이고 평화로운 정보를 } \\
\text { 선택하고 생산하는 힘을 기른다. }\end{array}$ \\
\hline
\end{tabular}

주차별 교육 목표와 주제는 [표 2]에 제시 되어있다.

[표 2] 주차별 교육 목표와 주제

[Table 2] Weekly Education Goals and Topics

\begin{tabular}{|c|c|c|c|}
\hline 단계 & 목표 & 주차 & 목표와 주제 \\
\hline \multirow{4}{*}{ 1단계 } & \multirow{4}{*}{$\begin{array}{c}\text { 뇌에 대한 이해 } \\
\text { (몸, 마음, 뇌의 관계) }\end{array}$} & 1 & 뇌의 3 층 구조와 기능, 시냅스와 학습, 뇌발달의 원리 \\
\hline & & 2 & $\begin{array}{c}\text { 몸 감각 깨우기, 긴장과 이완, 뇌체조(스트레칭, } 6 \text { 대 } \\
\text { 관절운동, 전신조타, 회전운동) }\end{array}$ \\
\hline & & 3 & $\begin{array}{c}\text { 몸에 의식 집중하기, 에너지 느끼기, 호흡(가슴호흡, } \\
\text { 뇌호흡) }\end{array}$ \\
\hline & & 4 & 명상(천문명상, 호흡명상, 에너지 집중명상, 음악명상) \\
\hline \multirow{4}{*}{ 2단계 } & \multirow{4}{*}{ 감각과 뇌 / 감정과 뇌 } & 5 & 마음의 감각 깨우기, 두뇌개발, 감각느낌(Felt Sense) \\
\hline & & 6 & 움직임과 감정: ‘행복한 액션이 행복을 창조한다' \\
\hline & & 7 & $\begin{array}{c}\text { 스트레스와 뇌(스트레스와 집중력, 기억력, 학습과의 } \\
\text { 관계) }\end{array}$ \\
\hline & & 8 & 긍정 정서의 힘, 협동게임, 실수 $\mathrm{OK}$, 사랑주기 \\
\hline \multirow{4}{*}{ 3단계 } & \multirow{4}{*}{ 정보와 뇌 } & 9 & 뇌 감각 깨우기, 정보와 뇌: 긍정 메세지와 가능성 \\
\hline & & 10 & 비전 설정, 선택하면 이루어진다. \\
\hline & & 11 & 자신에게 주는 메시지: 자기선언 \\
\hline & & 12 & 정보관리의 주체로서의 나, 선택과 창조자로서의 나 \\
\hline
\end{tabular}

\section{5 통계 분석}

본 연구에서 사용된 통계프로그램은 SPSS 25이며, 본 프로그램의 효과검증을 위해서 
평균, 표준편차 및 반복측정 분산분석(Repeated Measures ANOVA)를 사용하였다.

\section{4. 연구결과}

\section{1 평균 및 표준편차}

먼저, [표 3]에는 사전검사와 사후검사 및 추후검사에 대한 학업 효능감 척도의 평균과 표준편차가 실험집단과 통제집단 각각 제시되었다.

[표 3] 학업 효능감 척도의 평균 및 표준편차

[Table 3] Mean and Standard Deviation of the Academic Efficacy Scale

\begin{tabular}{|c|c|c|c|c|c|c|c|c|c|c|c|c|}
\hline \multirow{2}{*}{ 집단 } & \multicolumn{3}{|c|}{ 과제난이도 } & \multicolumn{3}{|c|}{ 자기조절 } & \multicolumn{3}{c|}{ 자신감 } & \multicolumn{3}{c|}{ 전체 } \\
\hline & 사전 & 사후 & 추후 & 사전 & 사후 & 추후 & 사전 & 사후 & 추후 & 사전 & 사후 & 추후 \\
\hline \multirow{2}{*}{ 실험 } & $\begin{array}{c}3.17 \\
(.87)\end{array}$ & $\begin{array}{c}3.60 \\
(.74)\end{array}$ & $\begin{array}{c}3.72 \\
(.79)\end{array}$ & $\begin{array}{c}3.39 \\
(.78)\end{array}$ & $\begin{array}{c}3.73 \\
(.64)\end{array}$ & $\begin{array}{c}3.80 \\
(.64)\end{array}$ & $\begin{array}{c}3.02 \\
(1.0)\end{array}$ & $\begin{array}{c}3.57 \\
(.82)\end{array}$ & $\begin{array}{c}3.62 \\
(.82)\end{array}$ & $\begin{array}{c}3.19 \\
(.74)\end{array}$ & $\begin{array}{c}3.63 \\
(.65)\end{array}$ & $\begin{array}{c}3.76 \\
(.63)\end{array}$ \\
\hline \multirow{2}{*}{ 통제 } & $\begin{array}{c}3.61 \\
(.87)\end{array}$ & $\begin{array}{c}3.61 \\
(.62)\end{array}$ & $\begin{array}{c}3.73 \\
(.84)\end{array}$ & $\begin{array}{c}3.72 \\
(.76)\end{array}$ & $\begin{array}{c}3.85 \\
(.69)\end{array}$ & $\begin{array}{c}3.92 \\
(.65)\end{array}$ & $\begin{array}{c}3.58 \\
(.89)\end{array}$ & $\begin{array}{c}3.77 \\
(.70)\end{array}$ & $\begin{array}{c}3.70 .( \\
.74)\end{array}$ & $\begin{array}{c}3.64 \\
(.67)\end{array}$ & $\begin{array}{c}3.74 \\
(.59)\end{array}$ & $\begin{array}{c}3.78 \\
(.60)\end{array}$ \\
\hline
\end{tabular}

\section{2 반복측정 분산분석(Repeated Measure ANOVA)}

학업 효능감 척도에 대한 반복측정 분산분석을 한 결과, 유의미한 프로그램의 효과가 나타난 변인은 '과제 난이도 요인' 과 '전체요인' 에서 유의미한 $(\mathrm{p}<.05)$ 수준에서 프로그램의 효과가 나타났다. 즉, 통합적 뇌활용 프로그램은 중국 7 학년 청소년들의 학업 효능감에 긍정적 영향을 미치는 것으로 밝혀졌다. 특히, 과제 난이도 요인에서 긍정적 영향을 미치는 것으로 확인되었다.

그 결과표는 [표 4]와 같다. 이는 학업 효능감의 하위요인인 과제 난이도 요인과 전체요인에서 사전·사후·추후의 효과가 집단에 따라 다른 것으로, 통합적 뇌활용 프로그램을 실시한 집단은 사전 ·사후·추후의 효과가 크게 나타난 반면에, 프로그램을 실시하지 않은 통제집단은 큰 변화가 없는 것으로 해석할 수 있다.

[표 4] 학업 효능감 척도에 대한 반복측정 분산분석표

[Table 4] Repeated Measures ANOVA Table for Academic Efficacy Scale

\begin{tabular}{|c|c|c|c|c|c|c|}
\hline \multirow{2}{*}{ 학업 효능감 척도 } & 효과 & $\begin{array}{c}\text { Type II Sum } \\
\text { of Squares }\end{array}$ & df & Mean Square & F & $\mathrm{p}$ \\
\hline \multirow{3}{*}{ 과제 난이도 } & 집단 & 1.167 & 1 & 1.167 & 0.819 & \\
\cline { 2 - 8 } & Error & 91.194 & 64 & 1.425 & & \\
\cline { 2 - 8 } & 시기 & 3.767 & 1 & 3.767 & 11.761 & $* * *$ \\
\cline { 2 - 8 } & 집단*시기 & 1.506 & 1 & 1.506 & 4.702 & $*$ \\
\cline { 2 - 8 } & Error & 20.502 & 64 & 0.32 & & \\
\hline
\end{tabular}




\begin{tabular}{|c|c|c|c|c|c|c|}
\hline \multirow{5}{*}{ 자기조절 효능감 } & 집단 & 1.842 & 1 & 1.842 & 1.909 & \\
\hline & Error & 61.768 & 64 & 0.965 & & \\
\hline & 시기 & 3.061 & 1 & 3.061 & 9.733 & $* *$ \\
\hline & 집단*시기 & 0.361 & 1 & 0.361 & 1152 & \\
\hline & Error & 20.044 & 64 & 0.313 & & \\
\hline \multirow{5}{*}{ 자신감 } & 집단 & 4.985 & 1 & 4.985 & 3.441 & \\
\hline & Error & 86.936 & 60 & 1.449 & & \\
\hline & 시기 & 3.834 & 1 & 3.834 & 8.638 & $* *$ \\
\hline & 집단*시기 & 0.818 & 1 & 0.818 & 1.842 & \\
\hline & Error & 26.631 & 60 & 0.444 & & \\
\hline \multirow{5}{*}{ 전체 } & 집단 & 2.447 & 1 & 2.447 & 2.438 & \\
\hline & Error & 60.224 & 60 & 1.004 & & \\
\hline & 시기 & 3.336 & 1 & 3.336 & 18.029 & $* * *$ \\
\hline & 집단*시기 & 0.822 & 1 & 0.822 & 4.444 & * \\
\hline & Error & 11.102 & 60 & 0.128 & & \\
\hline
\end{tabular}

[표 4]의 결과를 그림으로 나타내면 [그림 2]와 같다. [그림 2]는 실험집단과 통제집단의 하위 척도에 대해 사전점수와 사후점수 및 추후점수를 그래프로 나타낸 것으로 상호작용의 효과를 잘 보여주고 있다. 이러한 결과는 실험집단이 통제집단보다 과제 난이도 요인과 전체 요인에서 유의미한 향상이 있었음을 보여주고 있다.

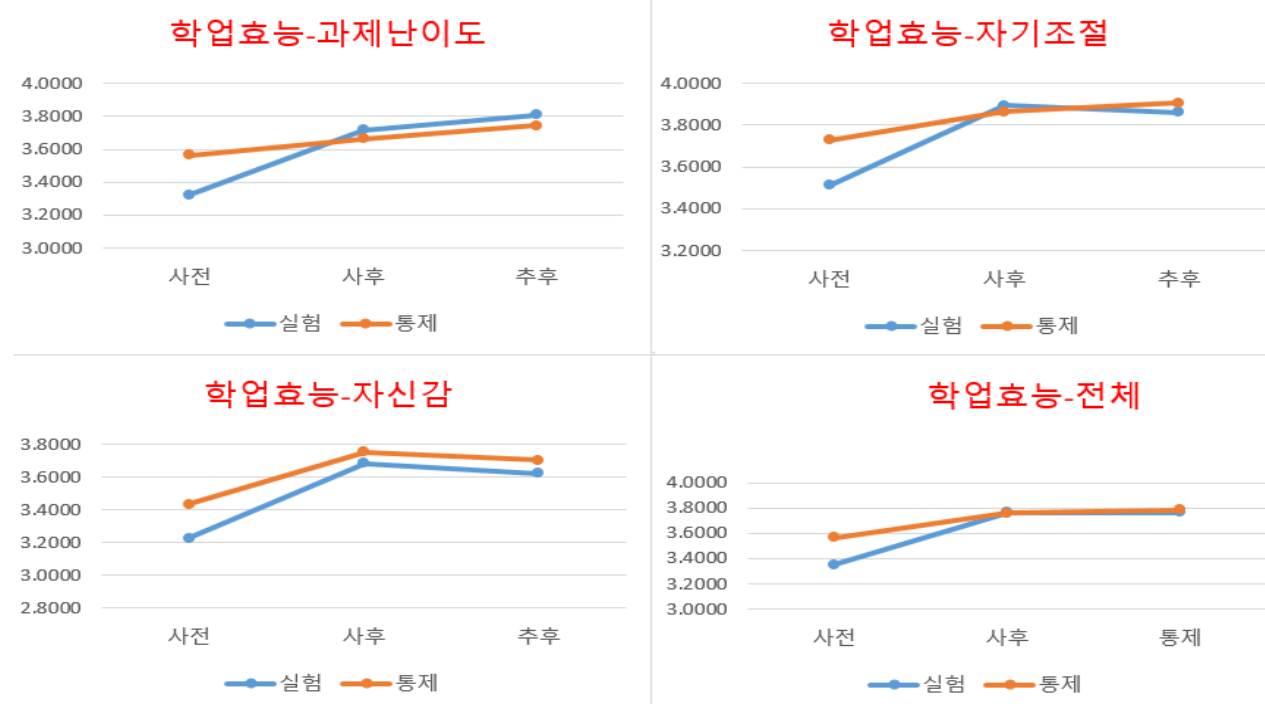

[그림 2] 검사 시기에 따른 학업 효능감 점수의 집단간 평균 비교

[Fig. 2] Intergroup Mean Comparison of Academic Efficacy Scores by Test Period

\section{5. 논의 및 결론}

본 연구는 중국 청소년의 학업 효능감 향상을 위한 통합적 뇌활용 프로그램의 효과를 검증하는 것을 목적으로 하였다. 먼저, 몸의 움직임, 호흡, 및 명상을 중심으로 몸, 마음, 정신을 골고루 자극하는 통합적 뇌활용 프로그램을 구성하였고, 프로그램의 효과를 검증하기 위해 7학년 83명을 대상으로 12 주 동안 프로그램을 적용하였다. 결과를 종합하여 결론을 내리고 논의를 하면 다음과 같다.

연구 결과, 학업 효능감 척도에서 통합적 뇌활용 프로그램은 유의미한 효과가 
나타났다. 특히, 과제 난이도 하위척도와 전체척도에서 유의미한 효과가 나타나 통합적 뇌활용 프로그램은 중국 청소년의 학업 효능감을 향상시키는 것으로 결론 내릴 수 있다. 학업 효능감의 하위요인 중에 특히 '과제 난이도' 요인에서 유의미한 긍정적 효과가 나타났다. 과제 난이도는 '나는 복잡하고 어려운 문제에 도전하는 것이 재미있다' , '나는 쉬운 문제보다 어려운 문제를 더 좋아한다', '시간이 오래 걸리더라도 깊이 생각하게 만드는 문제가 재미있다' 와 같이 학업적 측면에서 어려운 수준의 문제에 도전하고자 하는 특성을 의미한다. 이러한 결과는 한국의 학생들을 대상으로 통합적 측면에서 두뇌 활용 프로그램을 개발하고 그 효과를 검증하고자 했던 선행 연구[27]와 일치하는 결과이다. 이러한 결과는 본 프로그램이 뇌 가소성을 촉진시키고 자신감을 가지고 어렵고 낮선 과제에 도전하는 것을 장려하는 특성을 반영한 것으로 해석할 수 있다.

또한, 뇌의 3 층 구조의 통합적 접근을 취하고 있는 본 프로그램의 원리를 Jensen[10]의 학교 교육에 대한 원칙에 비추어 해석될 수 있다. 그는 체육활동이나 학습 내에서의 신체적 움직임은 학습에 중요한 요인으로 작용한다고 보고 있다. 운동은 새로운 뇌세포의 생성인 신경 발생과 매우 밀접한 상관관계가 있고 신경의 연결은 학습 및 기억력 개선과 상관관계가 있으며, 우울감을 감소시키며, 운동을 통해 뇌에 혈액과 산소의 공급을 증진시켜 학습하는 동안 뇌가 활발하게 활동하는 데 도움을 준다고 밝히고 있다.

또한 Jensen은 사회적 관계가 뇌에 영향을 미친다고 보고하고 있다. 이러한 사실은 거울뉴런의 발견으로 확인되었는데, 사회적 관계가 빈약하거나 고립되어 사회적으로 실패한 사람의 경우 뇌세포가 적은 것으로 밝혀져, 학생들의 학업적 향상이나 학업적 자신감을 위해서는 학교에서 친 사회적 조건을 강화하도록 의도적으로 사회적 그룹을 만들어 주어야 한다고 강조하고 있다.

이러한 연구 결과에 근거하여, 통합적 뇌활용 프로그램에 다수 포함된 친 사회적 활동(협동게임, 사랑주기, 실수 $\mathrm{K}$, 긍정정서)은 두뇌 친화적인 활동들이라고 할 수 있다. 이 프로그램에 참여한 학생들은 이러한 두뇌 우호적인 활동들을 통해 "학급 분위기가 달라졌어요” , “친구들과의 관계가 좀 더 친해지고 기분이 좋아졌어요” 와 같은 피드백을 하였다. 이러한 긍정적 학급 분위기가 학업적 자기효능감의 향상이라는 결과로 연결되었을 것으로 추론할 수 있다.

다미주 신경이론에 따르면, 우리의 뇌는 '안전' 을 최우선으로 여기기 때문에, 긴장과 스트레스 및 불안한 상태에서는 어떠한 좋은 교육도 뇌에서의 원활한 정보처리가 어렵다. 통합적 뇌활용 프로그램에서는 정서조절 활동들이 다수 포함되어 있다. 신체적 움직임과 명상, 두뇌 우호적 환경을 통해, 좋은 정보를 받아들일 수 있는 편안하고 안정된 정서 순화의 단계를 거쳐 정보를 수용할 수 있는 뇌 상태를 만드는 것을 학습의 선행조건으로 본다.

통합적 뇌활용 프로그램에서는 먼저 체조를 통해 몸과 마음을 이완시키는 것으로 시작한다. 다양한 신체활동 중에서 뇌 체조는 몸을 움직일 때, 의식을 몸에 두도록 유도한다. 예를 들어, 팔을 비틀기, 머리 두드리기, 허리 돌리기 등을 할 때, "팔에 의식을 집중하시고 팔의 어느 부위가 당겨지고 통증이 느껴지는지 느껴보세요” , "머리를 두드릴 때, 뇌에서 느껴지는 감각에 집중해보세요. 그리고 거기에 머물러보세요” 등의 메시지를 통해 “내적 몸 감각(inner body sensation)을 느낄 수 있도록 안내한다. 이러한 활동들은 유진 젠들린이 그의 저서 'Focusing' 에서 언급한 
감각 느낌(felt sense)을 개발하는 데 매우 유용한 활동이다. 감각 느낌을 통해 우리는 우리의 내면에서의 변화가 언제 어떻게 일어나는지 스스로 인지하고 경험할 수 있도록 도와준다. 내면의 신체 감각에 주의를 기울이다 보면 감각 느낌을 키울 수 있다.

젠들린에 따르면, 감각 느낌을 익히면 자신이 가진 많은 문제에 대해 몸이 스스로 해답을 알려주기 때문에 감각 느낌은 개발되어야 할 매우 중요한 감각이라고 하였다. 이러한 감각 느낌은 미주신경의 상향식 소통 방법을 통해 뇌에 전달되고 또다시 뇌는 하향식 전달방식을 통해 몸에 신호를 전달하는 과정을 반복하면 뇌의 발달에 기여한다고 볼 수 있다. 따라서, 본 프로그램은 미주신경이 양 방향적 소통을 원활하게 할 수 있도록 몸과 마음과 뇌의 조건을 형성해준다는 측면에서 그 의미가 크다고 할 수 있다.

또한, 본 프로그램에서 진행된 에너지 집중명상, 호흡명상 및 천문 명상 등 다양한 명상을 하는 동안 학생들의 뇌가 이완된 집중상태에 도달했을 것으로 보인다. 대부분의 명상활동은 뇌파를 알파파에서 세타파 상태에 이르게 한다. 알파파나 세타파와 같은 뇌의 이완된 집중상태는 기억 및 창의성과 직접적으로 관련되는데, 그 관련성에 대해서는 이미 제시된 바 있다[28]. 또한 이완된 집중상태일 때에는 많은 신경망이 동시에 활성화되어 연상망(association network)에서 멀리 떨어져 있는 시냅스 간의 연결이 용이하여 창의성 발현도 용이해진다. 이러한 선행연구에 비추어볼 때, 이완된 집중 상태는 모든 학습의 기초가 되는 기억의 과정이나 고차적 학습인 창의성 발현 기여함을 알 수 있다.

특히, 에너지집중 명상은 고요히 눈을 감고 양 손바닥이 마주 보게 손바닥을 펴서 손바닥 사이를 넓혔다 좁히기를 반복하면서 에너지를 느끼거나 천천히 호흡하면서 호흡에 주의를 집중하는 일련의 활동으로, 평화, 기쁨, 사랑, 자비의 정서들을 느끼게 되고 자신의 정서적 상태를 의식적으로 통제함으로써 기분 상태를 보다 적응적으로 끌어내며 가치 있는 목표를 향하여 동기를 부여할 수 있었을 것이다.

명상은 심리적 고통 감소를 위한 메커니즘을 유발하는 교감신경계의 과동한 활성화를 감소시킨다. 스트레스를 현저히 줄이고 건강한 뇌기능을 촉진할 수 있어 학교의 목표를 달성하기 위한 수단으로서 관련이 있음[29]에도 불구하고, 학교 교육에 깊이 뿌리내리지 못하는 데에는 명상이 주의집중 시간이 짧은 아동. 청소년에게 지루한 활동으로 인식되기 때문이다. 본 프로그램에서는 이러한 점을 고려하여 뇌체조, 움직임 명상(에너지볼 느끼기), 게임, 웃음 수련 등 몇 가지 즐겁고 유쾌한 분위기를 유발하는 활동을 적용한 것이 유효하였을 것으로 생각된다.

마지막으로 본 연구의 의의에 대해서 언급하고자 한다. 지금까지의 학교 교육은 외부로부터 지식이나 기능을 습득하는 방식의 뇌 개발에 주요 관심을 둔 나머지, 자신의 내적 상태를 이해하고 개발하는 데에는 소홀히 해왔었다. 이러한 교육적 현실에서, 우리나라와 유사하게 학업 스트레스가 높은 중국 청소년들을 대상으로, 두뇌 활용적 측면에서 피질에 초점을 맞추고 있는 현 교육에 대한 대안으로 3 층 뇌의 통합을 구현한 프로그램을 제시하고 그 효과를 검증하였다는 측면에서 본 연구의 의의가 있다. 앞으로 이러한 통합적 뇌활용 프로그램을 도입하는 것은 3층 뇌의 통합을 활성화 시켜 학업적 향상뿐만 아니라 정서조절 및 다양한 인간관계를 포함하여 학교 교육의 질 개선에 기여할 것으로 보인다.

본 연구는 다음과 같은 제한점을 가지고 있다.

첫째, 본 연구의 대상이 한 개 학교 학생들에게 적용한 결과이기 때문에, 타 학교에 일반화하기 어렵다. 
둘째, 학업성적을 비교적 중요시하는 학교 분위기 속에서, 낮선 외부의 강사가 지도하는 낮선 프로그램에 학생들이 집중하는 것이 쉽지 않았을 것이다.

이러한 제한점에도 불구하고 학업 효능감이라는 변수에서 유의미한 긍정적 효과가 나타난 것은 고무적인 결과로 평가할 수 있다.

마지막으로, 앞으로의 연구를 위하여 다음과 같이 제언하고자 한다.

첫째, 여러 학교를 대상으로 프로그램을 적용하여 연구 결과의 신뢰도를 높일 필요가 있다.

둘째, 학업에 집중해야 하는 중학생보다는 학업적 측면에서 좀 더 여유롭고 뇌 가소성이 보다 큰 초등학생들을 대상으로 뇌활용 프로그램을 적용해본다면, 신체, 정서 및 인지적 측면의 뇌 통합을 중요시하는 뇌활용 교육의 효과가 보다 잘 드러날 것으로 사료된다.

셋째, 본 연구의 결과는 자기보고 검사를 활용한 것으로, 앞으로는 능력 검사나 뇌파검사 같은 뇌의 현상을 가시적으로 나타내는 검사를 통해 프로그램의 기제를 밝히는 연구가 필요하다.

\section{6. 감사의 글}

본 연구는 2020년도 국제뇌교육협회(IBREA)의 지원을 받아 연구되었음

\section{References}

[1] A. Bandura, Social Foundation of Thought and action: A Social cognitive theory, Prentice-Hall, (1985)

[2] W. J. Park, The Effect of Perceived Parental Academic Involement on Adolescents' Career Aspiration: Focusing on Self-Directed Learning, Academic Self-Efficacy, and Outcome Expectancy, Daegu University, Ph.D dissertation, (2010)

[3] https://www.oecd.org/pisa/publications/pisa-2018-results.htm, Jun 28 (2021)

[4] M. S. Kim, The subjective Well-being of Korean Children and Its Policy Implications, Health and Welfare Policy Forum, (2015), Vol.220, pp.14-26.

[5] P. D. MacLean, The Triune Brain in Evolution: Role in Paleocerebral Functions, Springer, (1990)

[6] P. A. Levine, Healing trauma: A pioneering program for restoring the wisdom of your body, Sounds True, (2008)

[7] Daniel J. Siegel, Pocket guide to interpersonal neurobiology: an integratvie handbook of the mind, W. W. Norton \& Company, (2012)

[8] J. E. LeDoux, The Emotional Brain : The Mysterious Underpinnings of Emotional Life, Simon \& Schuster, (1996)

[9] C. R. Beamish, Knowledge about the brain for parents, students, and teachers: The keys to removing the invisible roadblocks to learning and high self-esteem for all students, The Proceeding of the Oregon Conference Monograph, (1995), February 2-4; Eugene, Oregon.

[10] E. Jensen, Teaching with the brain in mind, Association for Supervision and Curriculum Development, (1998)

[11] D. Loyd, Education's new pole-sitter : Brain-compatible theory and integrated thematic instruction, Paper presented at the Annual International Convention of the Council for Exceptional Children, (1995), April 5-9; Indianapolis, IN.

[12] Kyung-Ae Kim, The Effects of Self-esteem and Self-realization of Students with Intellectual Disability on BrainGymnastics Training Program, Journal of Intellectual Disabilityes, (2008), Vol.10, No.4, pp.79-96, UCI: G704001769.2008.10.4.001 
[13] You-Me Kim, The significance and application of emotion in the teaching-learning process : Based on brain-scientific approach, The Journal of Korean Education, (2003), Vol.30, No.1, pp.155-176, UCI: G704-000419.2003.30.1.001

[14] Mi-Kyoung Oh, The Study on the Effects of Brain Education for Positive Emotion and Emotion Regulation, Youth Facilities and Environment, (2015), Vol.13, No.4, pp.219-228, UCI: G704-001838.2015.13.4.018

[15] Juwon Oh, Nah Ok Kim, Effects of Brain Education-based Simsung Training on Stress Response and Interpersonal Problems in Adults, Asia-pacific Journal of Multimedia Services Convergent with Art, Humanities, and Sociology, (2019), Vol.9, No.8, pp.637-650, DOI: 10.35873/ajmahs.2019.9.8.056

[16] Yun Jin Lee, Jae Han Shin, A Study on the Impact of the Brain-education-based Meditation Program on the Brain Waves and Brain Utilization Abilities of Teenagers, The Journal of Learner-Centered Curriculum and Instruction, (2020), Vol.20, No.22, pp.717-734, DOI: 10.22251/jlcci.2020.20.22.717

[17] Stephen W. Porges, The polyvagal theory: Neurophysiological foundations of emotions, attachment, communication, and self-regulation (Norton series on interpersonal neurobiology), W. W. Norton \& Company, (2011)

[18] Stephen W. Porges, Social engagement and attachement: a phylogenetic perspective, Annals of the New York Acdemy of Sciences, (2003), Vol.1008, No.1, pp.31-47, DOI: 10.1196/annals.1301.004

[19] Stephen W. Porges, Neuroception: A Subconscious System for Detecting Threats and Safety, Zero to Three, (2004), Vol.24, No.5, pp.19-24.

[20] https://www.rubyjowalker.com/polyvagal_theory.html, Jun 28 (2021)

[21] Stephen W. Porges, The Pocket Guide to the Polyvagal Theory, W.W.Norton \& Company, (2017)

[22] A. Damasio, The feeling of what happens: Body and emotion in the making of consciousness, Harcourt Brace, (1999)

[23] B. A. van der Kolk, The Body Keeps the Score, Penguin Publishing Group, (2014)

[24] Minton Kekuni, Ogden Pat, Pain Clare, Trauma and the Body: A Sensorimotor Approach to Psychotherapy, W.W. Norton \& Compay, (2006)

[25] Min-Hye Jang, The Effect of Parenting Behavior and Parent-Child Communication as Perceived by Adolescents on Academic Efficacy and Academic Stress, Incheon National University, Master's thesis, (2015)

[26] Seung-Heon Lee, The Principles of Brain Education, University of Brain Eucation Press, (2010)

[27] Jae-Soo Choi, The Effect of Brain Education Based Personality Program on Self-directed Learning - Mediated Effect of Mindset and Academic Self-Efficacy, Department of Counseling and Psychology, University of Brain Education, Ph.D dissertation, (2019)

[28] Hyoun-Kab Chang, Therapeutic Application of Meditation to the Stress-Related Disorders, Korean Journal of Health Psychology, (2004), Vol.9, No.2, pp.471-492, UCI: G704-000533.2004.9.2.002

[29] L. Valosek, S. Nidich, J. Grnat, M. Peterson, R. Nidich, Effect of meditaion on psychological stress and academic achievement in high school students: A randomised controlled study, Educaion, (2021), Vol.141, No.4, pp.192-200. 